\title{
Influence of osmotic dehydration and high temperature short time processes on dried sweet potato (Ipomoea batatas Lam.)
}

\author{
Graziella Colato Antonio ${ }^{\mathrm{a}, *}$, Denise Gomes Alves ${ }^{\mathrm{b}}$, Patrícia Moreira Azoubel ${ }^{\mathrm{c}}$, \\ Fernanda Elizabeth Xidieh Murr ${ }^{\mathrm{a}}$, Kil Jin Park ${ }^{\mathrm{a}}$

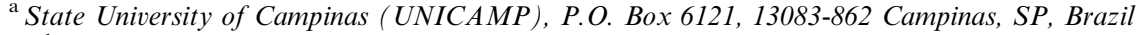 \\ ${ }^{\mathrm{b}}$ University of Tocantins (UFT) Av. NS 15, ALC NO-14, 77020-210 Palmas, TO, Brazil \\ ${ }^{\mathrm{c}}$ EMBRAPA Semi-Arid, BR 428, km 152, P.O. Box 23, 56302-97 Petrolina, PE, Brazil
}

Received 25 December 2006; received in revised form 16 May 2007; accepted 17 May 2007

Available online 5 June 2007

\begin{abstract}
The puffing operation is carried out at as intermediate stage in the drying process. When reconstituted, the dehydrated puffed product presents a more pleasing appearance than the material that has not been puffed. The high temperature and short time process (HTST) was employed to obtain puffed sweet potato slices from both in natura and osmotically pretreated with sucrose and salt solutions samples. Processing time was the most significant variable affecting moisture content, water activity and rehydration. All the empirical models obtained using response surface methodology were considered predictive. The best conditions for the HTST sweet potato slices were obtained using a temperature of $160{ }^{\circ} \mathrm{C}$ and time of $22 \mathrm{~min}$ for samples with no osmotic treatment and a temperature of $150{ }^{\circ} \mathrm{C}$ and time of $10 \mathrm{~min}$ for samples submitted to the osmotic treatment. Scanning electronic microscopy confirmed the formation of pores within the tissue, and surface sealing during the HTST process as the samples puffed up (volume increase). The shortest convective drying time corresponded to the sample treated only by the HTST process.
\end{abstract}

(C) 2007 Elsevier Ltd. All rights reserved.

Keywords: Puffing; Microstructure; Experimental design; Drying rate

\section{Introduction}

Sweet potato is one of the five most important food crops in developing countries. It is one of the most efficient food crops in terms of caloric value per cultivated area, being relatively easy to grow even in poor, dry soil. Tuber crops achieve levels of importance as great as cereal grains in providing the greater part of people's daily caloric needs in the tropics. The sweet potato shows significant nutritional contributions to the diet. It provides at least $90 \%$ of human requirements, except for protein and niacin (Bouwkamp, 1985), since the root part is rich in $\beta$-carotene, food fiber, and potassium ion, etc. Sweet potato is used

\footnotetext{
* Corresponding author. Tel.: +55 193521 1076; fax: +55 1935211010 . E-mail address: graziella.colato@agr.unicamp.br (G.C. Antonio).
}

widely in ready-to-eat foods such as noodles, Chinese style French fries, canned foods, etc.

The technique of dehydration is probably the oldest method of food preservation practiced by mankind. The use of artificial drying to preserve agricultural products has been expanding, creating a need for more rapid and efficient drying techniques and methods that reduce energy consumption and costs in the drying processes (Afzal, Abe, \& Hikida, 1999). Innovative techniques that increase drying rates and enhance product quality have acquired considerable attention.

The puffing operation is carried out at an intermediate stage in the drying process. The wet material is introduced into an environment at an elevated temperature for short time. A sudden increase in temperature causes the water within the cells of the material to vaporize and expand. A 


\section{Nomenclature}

$\begin{array}{ll}a_{\mathrm{w}} & \text { water activity } \\ b_{n} & \text { constant regression coefficients, Eq. (2) } \\ E & \text { average mean deviation (\%) } \\ \text { HTST } & \text { high temperature short time } \\ \text { IN } & \text { in natura } \\ M_{0} & \text { sample mass at time zero (dried samples) (g), } \\ & \text { Eq. (1) } \\ M_{\mathrm{t}} & \text { sample mass at time } t \text { (rehydrated samples) }(\mathrm{g}), \\ & \text { Eq. (1) } \\ n_{\mathrm{e}} & \text { number of experimental data, Eq. (3) } \\ \mathrm{OD} & \text { osmotically treated }\end{array}$

$\begin{array}{ll}R & \text { rehydration }(\%), \text { Eq. }(1) \\ R^{2} & \text { correlation coefficients } \\ T & \text { temperature }\left({ }^{\circ} \mathrm{C}\right) \\ t & \text { time }(\text { min) } \\ \mathrm{SEM} & \text { scanning electron microscopy } \\ V_{\mathrm{c}} & \text { calculated value } \\ V_{\mathrm{E}} & \text { experimental value } \\ X & \text { moisture content }(\%) \\ X_{1} & \text { code for process temperature }(-1,0,1), \mathrm{Eq} .(2) \\ X_{2} & \text { code for process time }(-1,0,1), \mathrm{Eq} .(2) \\ Y & \text { response variable }\left(\text { i.e. } X, a_{\mathrm{w}} \text { or } R\right), \mathrm{Eq} .(2)\end{array}$

puffing process involves the release or expansion of a gas within a product either to create an internal structure or to expand or rupture an existing structure. The effect of this operation is that further drying takes place more rapidly, and shrinkage of the product is greatly reduced. When reconstituted, the dehydrated puffed product presents a more pleasing appearance than material which has not been puffed (Varnalis, Brennan, \& MacDougall, 2001a). The quality of many dehydrated products is related to the retention of their internal pores and of the bulk volume of the original product, although there are various other effects which are of interest. A puffed product generally has a lower bacterial count. Under correct processing conditions, there is a drop in moisture content during the process itself, due to the flash evaporation of part of the water from the product. Other favorable characteristics of puffed products are their excellent flavor and color, fast rehydration, storage at ambient temperature, minimal storage and transportation costs and durability (Sullivan, Craig, Dekazos, Leiby, \& Konstange, 1982).

The purpose of the present experiments was to study the puffing process of sweet potato slices with and without osmotic pretreatment, and evaluate the optimum HTST process, image analysis of the products and sample pretreatment effects on the drying rate.

\section{Materials and methods}

\subsection{Preparation of sweet potato samples}

The sweet potato roots of the variety Mona Lisa were acquired from a local market. The samples were hand peeled and cut into $0.5 \mathrm{~cm}$ thick slices. The moisture content of the sweet potato was $70.0 \%$ on a wet basis.

\subsection{Analyses}

\subsubsection{Moisture content}

The moisture content was determined by drying samples in a vacuum oven at $70^{\circ} \mathrm{C}$ to constant weight (AOAC, 2000).

\subsubsection{Water activity}

The water activity $\left(a_{\mathrm{w}}\right)$ was determined using a dew point hygrometer Decagon CX-2.

\subsubsection{Rehydration}

The rehydration $(R)$ was evaluated by immersing a dried sweet potato sample in $500 \mathrm{ml}$ of boiling water for $20 \mathrm{~min}$. After this time the sample was taken out and blotted with paper towel to eliminate excess water on its surface. The mass of the dried and rehydrated samples were measured by an analytic balance. The rehydration of the sample was then calculated by

$R(\%)=\frac{M_{\mathrm{t}}-M_{0}}{M_{0}} \times 100$,

where $M_{t}$ and $M_{0}$ are the samples mass at time $t$ (rehydrated samples) and zero (dried samples), respectively.

All the experiments were carried out in triplicate and the average value was taken for the calculations.

\subsection{Osmotic treatment}

Experimental solutions were prepared with commercial sucrose and salt and distilled water at concentrations of $40 \% \mathrm{w} / \mathrm{w}$ of sucrose and $5 \% \mathrm{w} / \mathrm{w}$ of salt. The slices were placed in $250 \mathrm{~mL}$ beakers containing the osmotic solution at $40{ }^{\circ} \mathrm{C}$ and maintained in a temperature-controlled bath (Tecnal, TE 421). Homogenization of the osmotic solution was obtained by mild agitation at $80 \mathrm{rpm}$. The mass ratio of the osmotic medium to the sample was 10:1 to avoid significant dilution of the medium and subsequent decrease in driving force during the process. The samples were removed from the solution after $120 \mathrm{~min}$ of immersion, drained, and the excess solution on the surface removed using adsorbent paper.

\subsection{Puffing}

The puffing process was carried out in a closed chamber (high temperature fluidized bed) operating under constant ambient pressure. The chamber consisting of a stainless 
steel cylinder with a $0.2 \mathrm{~cm}$ wall thickness, $12 \mathrm{~cm}$ internal diameter and height of $27 \mathrm{~cm}$. The high temperature short time (HTST) processes were studied using an experimental design were fluidized bed at air temperature varying between 110 and $160{ }^{\circ} \mathrm{C}$ and time of the process between 5 and $25 \mathrm{~min}$. The air velocity maintained in $15 \mathrm{~m} / \mathrm{s}$.

\subsubsection{Experimental design}

Response surface methodology (RSM) was used to optimize the puffing process. RSM has been used by several investigators to optimize food process operations. A three level, two factor design (Box \& Behnken, 1960) was employed to optimize the HTST process of the sweet potato slices. It was assumed that two mathematical functions, $f_{\mathrm{k}}(k=1,2)$, exists for each response variable $(Y)$, in terms of two independent processing factors. The factors (independent variables) with an impact on the quality of the puffed sweet potato slices were considered to be: process temperature $\left(110-160^{\circ} \mathrm{C}\right)$ and time $(5-25 \mathrm{~min})$. The following attributes or responses (dependent variables) were considered in this study: moisture content $(X)$, water activity $\left(a_{\mathrm{w}}\right)$ and \% rehydration $(R)$. The design resulted in seven experiments with three replications at the central point, and RSM was applied to the experimental data using the commercial statistical package: Experimental Design version 5.0. The data was fitted to the following polynomial model:

$Y=b_{0}+b_{1} X_{1}+b_{2} X_{2}+b_{12} X_{1} X_{2}$,

where $Y$ is the response variable (i.e. $X, a_{\mathrm{w}}$ or $R$ ); $b_{n}$ are constant regression coefficients; $X_{1}$ is the code for process temperature $(-1,0,1)$ and $X_{2}$ is the code for process time $(-1,0,1)$.

Tables 1 and 2 show the independent variables used in the study and the experimental design, respectively. The statistical significance of the terms in the regression equation was examined. Figs. 1 and 2 show the response surfaces generated.

\subsubsection{Statistical analyses}

The criterion used to characterize the fitting efficiency of the data to the model was the multiple correlation coefficients $\left(R^{2}\right)$ and their average mean deviation $(E)$

Table 1

Code levels of the independent variables used for the puffing process of sweet potato slices

\begin{tabular}{lllllr}
\hline Independent variables & Symbols & & & Levels \\
\cline { 6 - 6 } \cline { 5 - 6 } & Uncoded & Coded & & Uncoded & Coded \\
\hline Temperature $\left({ }^{\circ} \mathrm{C}\right)$ & $T$ & $X_{1}$ & & 110 & -1 \\
& & & 135 & 0 \\
Time (min) & \multirow{2}{*}{$t$} & $X_{2}$ & & 160 & 1 \\
& & & & 15 & -1 \\
& & & 25 & 0 \\
\hline
\end{tabular}

Table 2

Combination of parameters for the experimental design for the puffing process of sweet potato slices

\begin{tabular}{llllll}
\hline Treatment no. & \multicolumn{2}{l}{ Uncoded } & & \multicolumn{2}{c}{ Coded } \\
\cline { 2 - 3 } \cline { 5 - 6 } & $T\left({ }^{\circ} \mathrm{C}\right)$ & $t(\min )$ & & $T\left({ }^{\circ} \mathrm{C}\right)$ & $t(\min )$ \\
\hline 1 & 110 & 5 & -1 & -1 \\
2 & 160 & 5 & +1 & -1 \\
3 & 110 & 25 & -1 & +1 \\
4 & 160 & 25 & +1 & +1 \\
5 & 135 & 15 & 0 & 0 \\
6 & 135 & 15 & 0 & 0 \\
7 & 135 & 15 & 0 & 0 \\
\hline
\end{tabular}
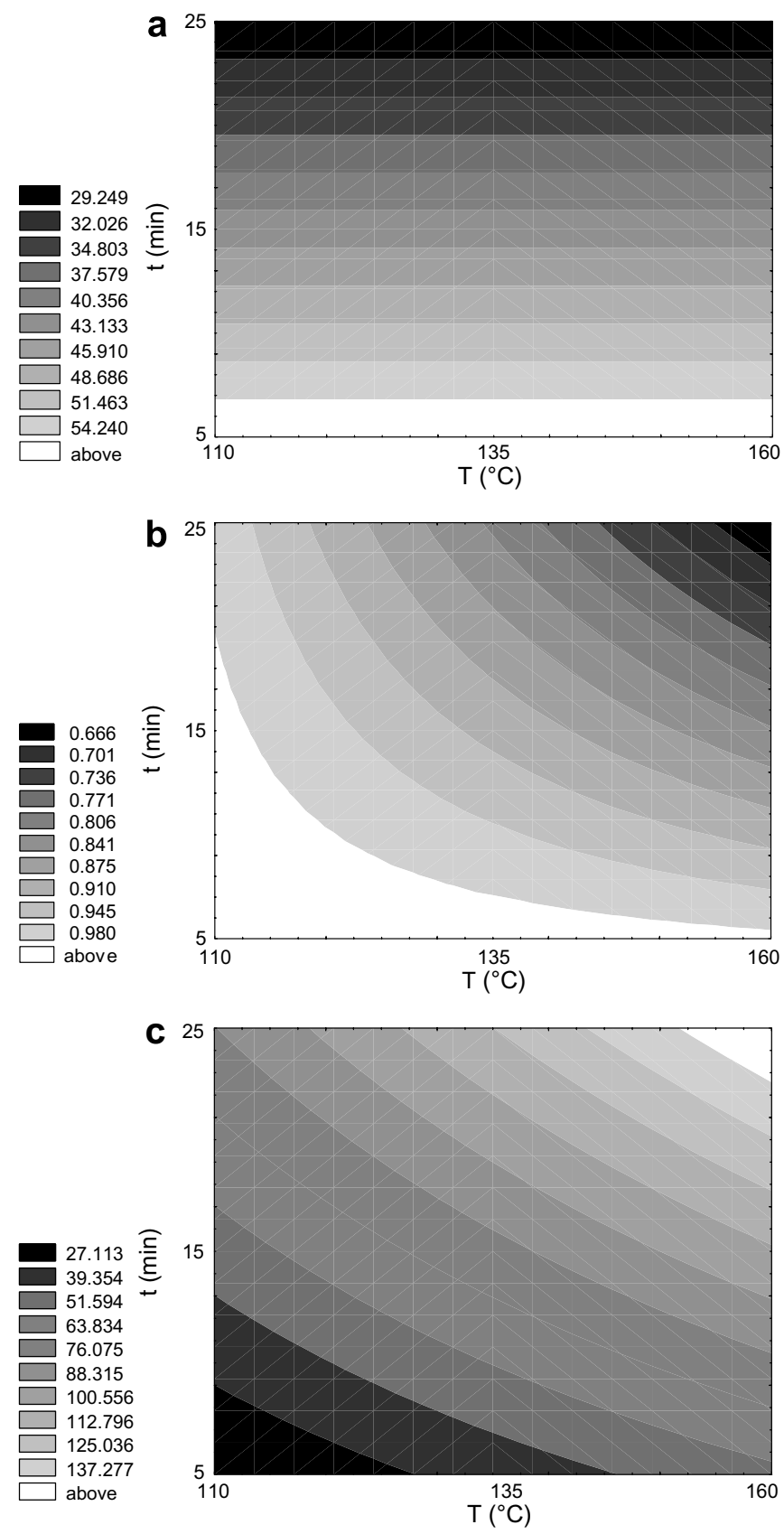

Fig. 1. Flat curves for (a) moisture content, (b) water activity and (c) rehydration for the HTST processing of sweet potato slices with no osmotic pretreatment. 
a

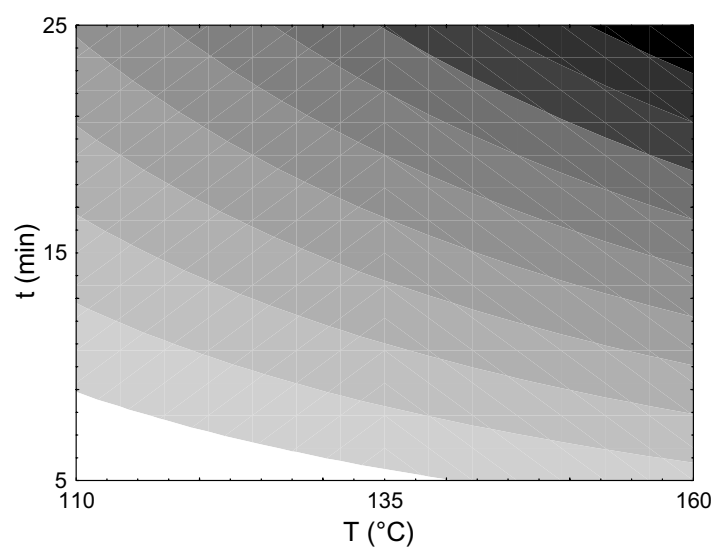

b

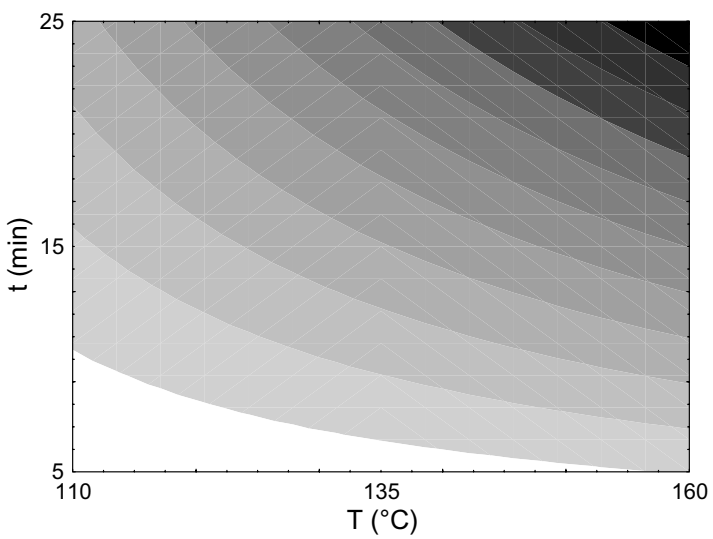

C

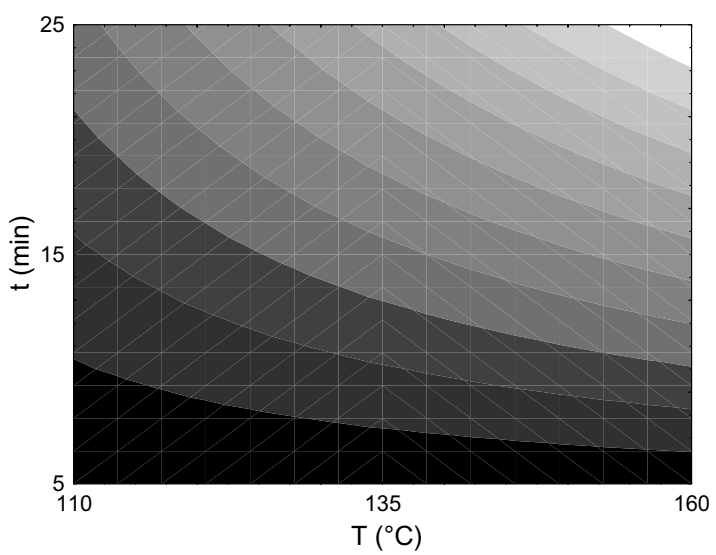

Fig. 2. Flat curves for (a) moisture content, (b) water activity and (c) rehydration for the HTST processing of sweet potato slices with osmotic pretreatment.
$E(\%)=\frac{1}{n_{\mathrm{e}}} \sum_{i=1}^{n_{\mathrm{e}}}\left\|\frac{V_{\mathrm{E}}-V_{\mathrm{c}}}{V_{\mathrm{E}}}\right\| 100$,

where $E$ is the average mean deviation, $n_{\mathrm{e}}$ is the number of experimental data, $V_{\mathrm{E}}$ is the experimental value and $V_{\mathrm{c}}$ is the calculated value.

\subsection{Microstructure studies}

The changes produced during the process were also studied using a JEOL model JSM 5800LV Scanning Electron Microscope at $5 \mathrm{kV}$. The samples were covered with gold in a Sputter Coater (BALZERS, model SCD050).

\subsection{Final convective drying}

Sweet potato slices were dried to a shelf stable final moisture content of $12 \%$ (wet basis) using a convective dryer at a temperature of $70{ }^{\circ} \mathrm{C}$ and an air velocity of $1.5 \mathrm{~m} \mathrm{~s}^{-1}$. Four types of sample were dried: in natura, osmotically pretreated, HTST pretreated and osmotically and HTST pretreated.

\section{Results and discussion}

\subsection{Effect of the parameters}

RSM was used to determine the optimum puffing process for sweet potato slices.

Table 3 shows the experimental results used in the response surface regression.

The results showed that the water activity $\left(a_{\mathrm{w}}\right)$ and \% rehydration $(R)$ were more affected by process time, followed by the temperature. The interaction of temperature and time was also significant for $a_{\mathrm{w}}$ and $R$ at a level of $5 \%$. For the moisture content $(X)$ the temperature and time interaction was not significant at the $5 \%$ level.

As shown in Table 3, visual conditions were considered to choose the best experimental design condition. It was shown that the osmotically pretreated samples resulted in burnt products during the HTST process when conducted at higher temperatures. Samples with no osmotic pretreatment only presented burnt products after long exposure times in the HTST process.

Table 3

Experimental data used for the response surface analysis

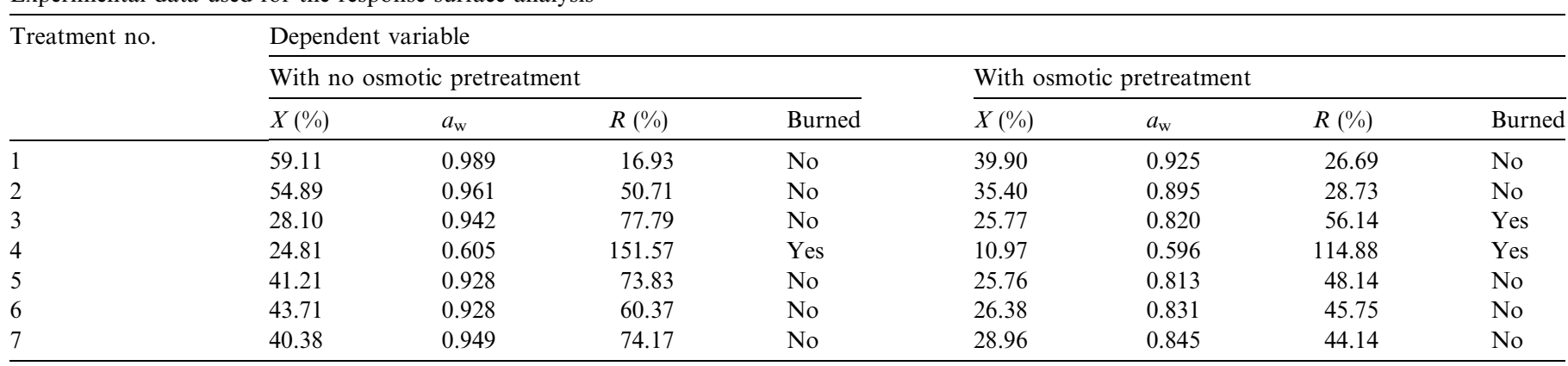


Table 4

Regression equation coefficients for moisture content $(X)$, water activity $\left(a_{\mathrm{w}}\right)$ and rehydration $(R)$ during sweet potato slice puffing

\begin{tabular}{|c|c|c|c|c|c|c|}
\hline \multirow[t]{2}{*}{ Coefficients } & \multicolumn{3}{|c|}{ With no osmotic pretreatment } & \multicolumn{3}{|c|}{ With osmotic pretreatment } \\
\hline & $X(\%)$ & $a_{\mathrm{w}}$ & $R(\%)$ & $X(\%)$ & $a_{\mathrm{w}}$ & $R(\%)$ \\
\hline$b_{0}$ & 41.74 & 0.92 & -52.66 & 27.59 & 0.82 & 41.49 \\
\hline $\begin{array}{l}\text { Linear } \\
b_{1} \\
b_{2}\end{array}$ & $\begin{array}{l}\mathrm{ns}^{*} \\
-15.27\end{array}$ & $\begin{array}{l}9 \times 10^{-4} \\
0.03\end{array}$ & $\begin{array}{r}0.47 \\
-1.36\end{array}$ & $\begin{array}{l}-4.82 \\
-9.64\end{array}$ & $\begin{array}{l}-0.06 \\
-0.10\end{array}$ & $\begin{array}{l}-0.24 \\
-4.76\end{array}$ \\
\hline $\begin{array}{l}\text { Interaction } \\
b_{12}\end{array}$ & $\mathrm{~ns}^{*}$ & $-3 \times 10^{-4}$ & 0.04 & -2.57 & -0.05 & 0.06 \\
\hline$R^{2}$ & 0.99 & 0.94 & 0.98 & 0.99 & 0.98 & 0.96 \\
\hline
\end{tabular}

${ }^{*} \mathrm{~ns}=$ not significant $(p \geqslant 5 \%)$.

Table 4 shows the regression equations describing the effect of the puffing process variables on the moisture content $(X)$, water activity $\left(a_{\mathrm{w}}\right)$ and \% rehydration $(R)$ of the sweet potato slices. High correlation coefficients $\left(R^{2}\right)$ were obtained for the responses, indicating a good fit of the experimental data to Eq. (2).

Figs. 1 and 2 present the contour surfaces and flat curves, respectively, for each response analyzed in the experimental design, with and without osmotic pretreatment.

Fig. 1 shows that the moisture content and water activity decreased with increase in process time. Increase in temperature also decreased the water activity, but was indifferent for moisture content.

The $\%$ rehydration was maximal under the conditions of $160{ }^{\circ} \mathrm{C}$ for times longer than $20 \mathrm{~min}$, conditions corresponded to the maximum increase in sample volume according to visual observation. Other authors (Jayaraman, Gopinathan, Pitchamuthu, \& Vijayaraghavan, 1982; Kim \& Toledo, 1987; Payne, Taraba, \& Saputra, 1989; Sullivan et al., 1982; Torreggiani, Toledo, \& Bertolo, 1995; Varnalis, Brennan, MacDougall, \& Gilmour, 2004), studying the HTST treatment of diverse products, also observed that the greatest rehydration coincided with the greatest puffing of the product.

Fig. 2 shows that the lowest moisture contents are reached with the use of the highest temperatures and longest process times. It was also shown that the lowest values for water activity were reached with the use of temperatures above $135^{\circ} \mathrm{C}$ and process times longer than $15 \mathrm{~min}$. The use of high temperatures and long process times resulted in a product with high \% rehydration.

\subsection{Optimization}

Optimization of the HTST process was carried out to obtain maximum puffing by way of low values for moisture content and water activity and high values for $\%$ rehydration of the processed product, associated with processing conditions that did not affect the appearance (visual) of the dried product.

To satisfy the objectives of the optimization of the HTST process, flat curves were generated for each experi- mental design response, which were then overlapped ( $X$, $a_{\mathrm{w}}$ and $R$ ). It is important to point out the optimized condition was also selected in agreement with visual observations of the samples, such as the color, the formation of puffing and the absence of non-enzymatic browning.

It was observed that for samples with no pretreatment, the desired condition was obtained when high temperatures and long process times were used. From a visual observation it was clear that the products processed at a temperature of $160{ }^{\circ} \mathrm{C}$ for long process times presented a good appearance, i.e. definitely yellow with no spots of enzymatic browning and maximum puffing. At this temperature, a time of $22 \mathrm{~min}$ was selected as excellent to obtain a product with the desired characteristics and maximum puffing, with the formation of a high number of internal pores in the tissue structure.

In the case of the process with osmotic pretreatment, visual observations were also used to determine maximum puffing and coloration of the product. These observations were relevant because it was observed that high temperatures and long process times, although resulting in lower moisture contents and water activity values, presented dark, hard products. This hardness was probably a result of the presence of sugar incorporated during the osmotic pretreatment, a phenomenon that increased the gelatinization temperature and limited water availability to the starch granules, forming a hard sample surface. As a function of this, the optimum conditions were defined as a process temperature of $150{ }^{\circ} \mathrm{C}$ with a time of $10 \mathrm{~min}$. Under these conditions the product presented good visual appearance, with an intense yellow color, no brown spots and maximum puffing, although it failed to achieve the minimum moisture content and water activity values.

\subsection{Scanning electron microscopy}

The reduced surface permeability forms a barrier to the escape of internal water as it vaporizes during the puffing process at high temperatures. As the water pressure increases within the sweet potato slices, it creates pressure against the walls from the inside to the outside, resulting in expansion, which produces a puffed product. 
As expected, the decreasing permeability of the osmotically treated slices with increasing HTST time yielded puffed slices with correspondingly higher volumes. This decrease in permeability of the osmotically treated samples may have been due to starch gelatinization on the surface with a reduction in porosity. Karathanos, Villalobos, \& Saravakos (1990) and Marousis, Karathanos, \& Saravakos (1991) reported that reduced water diffusivities were associated with the gelatinization of starchy materials.

Figs. 3 and 4 present the scanning electron microscopy images of the products.

Fig. $3 \mathrm{a}$ and $\mathrm{b}$ shows that the sample surface structure was not sealed, showing regions with open spaces and an irregular surface with cells with little turgor pressure, giving the impression of permeability on the surface. Under these conditions, there was no increase in sample volume, and hence no puffing. Similar results were observed by Varnalis, Brennan, \& MacDougall (2001b) when studying HTST in potato drying.

Fig. $3 \mathrm{~b}$ shows the central part of the slice, where there was no pore formation and the structure presented a completely irregular form, with loss of integrity of the cellular tissue and loose starch granules. Fig. $3 \mathrm{c}$ and d shows surface and center structures of in natura sample submitted to HTST at $160{ }^{\circ} \mathrm{C}$ for $25 \mathrm{~min}$ (experiment number 4 , more severe process conditions). It can be seen that the sample surface is completely sealed (homogeneous), probably due to starch gelatinization, which conferred an amorphous glassy image. Under these process conditions, intense sample puffing occurred. Using SEM, Varnalis et al. (2001b) showed the complete gelatinization of the starch in potato submitted to the HTST drying process. This gelatinization resulted in sealing of the sample surface and an increase in volume of the sample (puffing).

The surface of the slices not submitted to osmotic pretreatment (Fig. 3c), even under high magnification, was quite featureless. The starch granules are invisible and all the pores are covered with an intact layer, probably gelatinized starch.

It can be seen from Fig. 3d, that the center of the slice of the sample with no osmotic pretreatment, processed at $160{ }^{\circ} \mathrm{C}$ for $22 \mathrm{~min}$, was porous. Many of the starch granules were intact and therefore non-gelatinized.

In Fig. 4 the surface of the sample was more compact, but sealing had not occurred satisfactorily, presenting some cracks and evidence of partially gelatinized starch. There was some pore formation at the center of the slices, with the presence of some starch granules. With the osmotic pretreatment, an increase in the volume of the sample occurred, but to a lesser degree than in the sample with
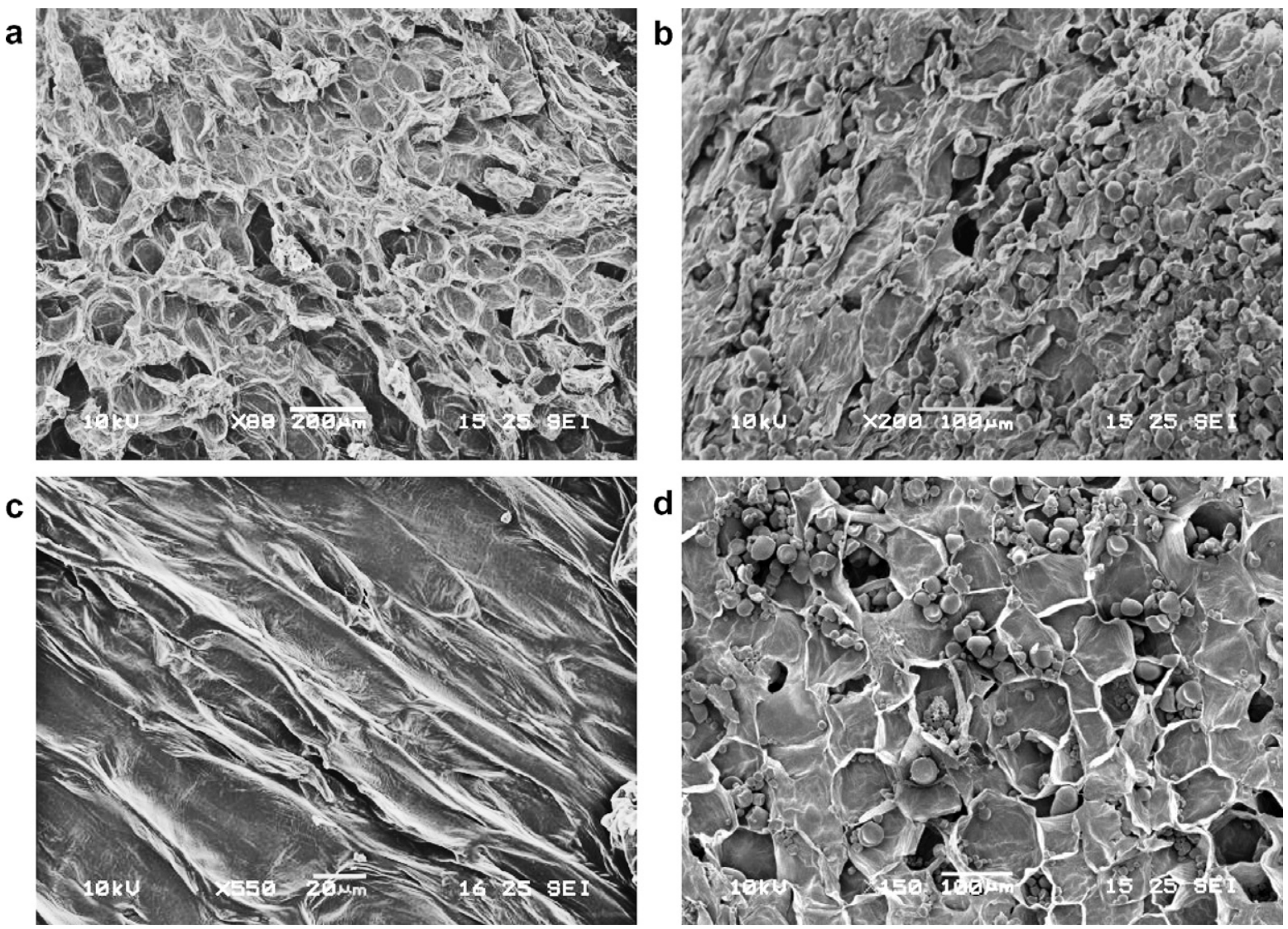

Fig. 3. Scanning electron microscopy (SEM) of HTST dried sweet potato slices with no osmotic pretreatment: (a) mag. $80 \times$, surface $-110{ }^{\circ} \mathrm{C}, 5 \mathrm{~min}$; (b) mag. $200 \times$, center $-110^{\circ} \mathrm{C}, 5 \mathrm{~min}$; (c) mag. $550 \times$, surface $-160{ }^{\circ} \mathrm{C}, 22 \mathrm{~min}$ and (d) mag. $150 \times$, center $-160{ }^{\circ} \mathrm{C}, 22 \mathrm{~min}$. 

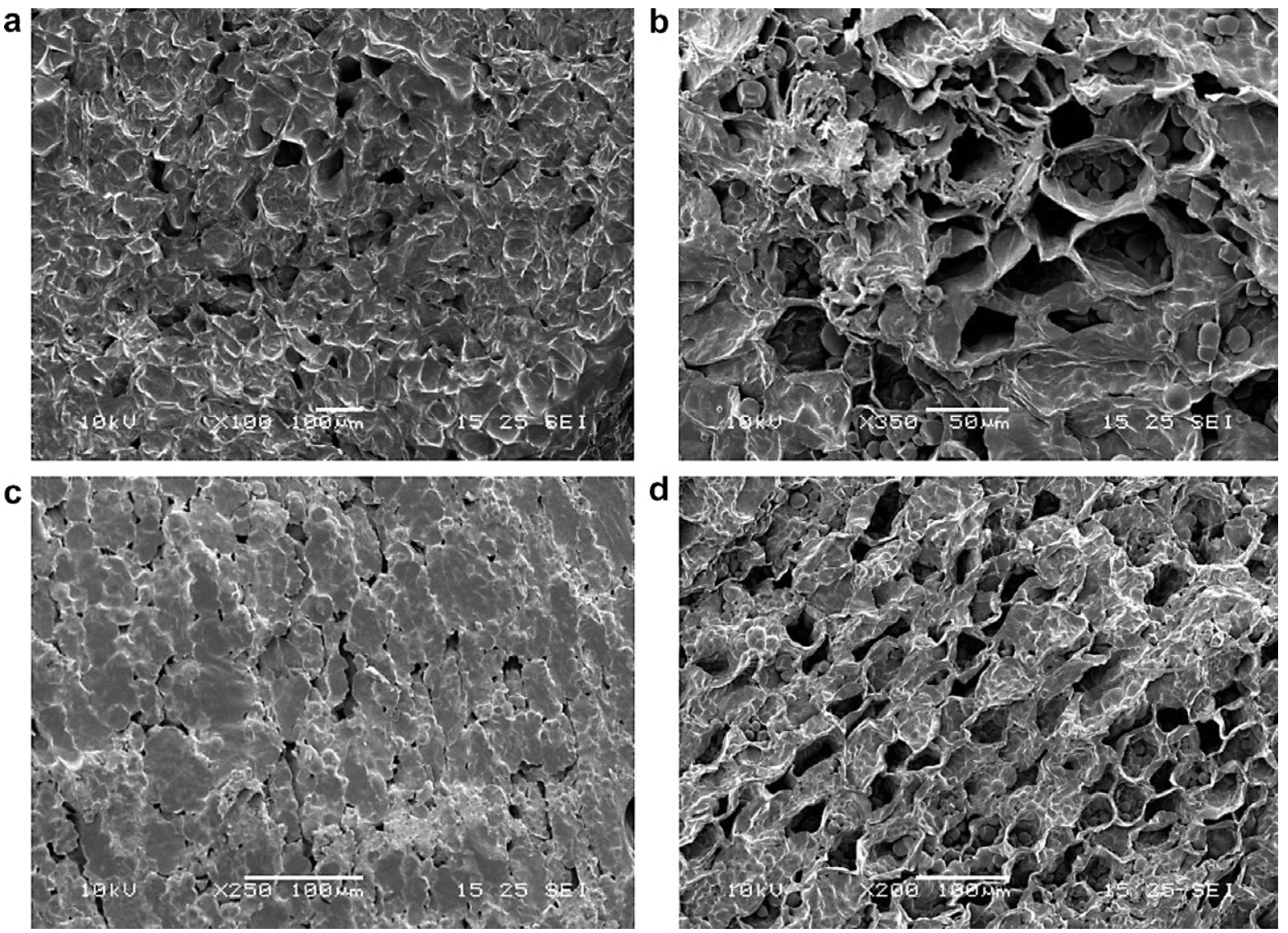

Fig. 4. Scanning electron microscopy (SEM) of HTST dried sweet potato slices with osmotic pretreatment $\left(40{ }^{\circ} \mathrm{C}, 50 \% \mathrm{w} / \mathrm{w}\right.$ sucrose, $5 \% \mathrm{w} / \mathrm{w}$ salt): (a) mag. $80 \times$, surface $-110^{\circ} \mathrm{C}, 5 \mathrm{~min}$; (b) mag. $200 \times$, center $-110^{\circ} \mathrm{C}, 5 \mathrm{~min}$; (c) mag. $550 \times$, surface $-160{ }^{\circ} \mathrm{C}, 22 \mathrm{~min}$ and (d) mag. $150 \times$, center $-160{ }^{\circ} \mathrm{C}$, $22 \mathrm{~min}$.

no osmotic pretreatment, considering the same HTST process conditions (Fig. 4c and d), probably due to the difference in porosity of the surface, generated by the osmotic treatment.

Comparing Fig. 3d and Fig. 4d, the cells of the dehydrated samples were shown to have partially lost their turgor pressure, showing fragile and corrugated cell walls.

Using electronic microscopy it was concluded that for samples with no osmotic pretreatment, HTST drying was efficient, with volume expansion (puffing) at high temperatures (about $160{ }^{\circ} \mathrm{C}$ ) and long process times (more than $20 \mathrm{~min}$ ). For the osmotically pretreated samples, HTST treatment at temperatures above $150{ }^{\circ} \mathrm{C}$ and long process times resulted in non-enzymatic browning, giving a burnt aspect and a very hard product. Therefore for these samples, the best conditions for the HTST drying were a temperature of $150{ }^{\circ} \mathrm{C}$ and process time of $10 \mathrm{~min}$, although the acquired volume was still less than that acquired without osmotic pretreatment.

\subsection{Final convective drying}

Table 5 presents the total drying time of sweet potato slices up to a final moisture content of $12 \%$ (wet basis),
Table 5

Total drying time of sweet potato slices to a final moisture content of $12 \%$ (wet basis)

\begin{tabular}{llc}
\hline Treatment & $\begin{array}{l}\text { Initial moisture } \\
\text { content }(\%)\end{array}$ & $\begin{array}{l}\text { Drying time } \\
(\mathrm{min})\end{array}$ \\
\hline In natura (IN) & 69.70 & 96 \\
Osmotically treated (OD) & 41.06 & 137 \\
HTST & 16.63 & 20 \\
OD + HTST & 28.09 & 205 \\
\hline
\end{tabular}

Osmotic and HTST process time excluded.

and Fig. 5 shows the drying rates using a convective dryer at $T=70{ }^{\circ} \mathrm{C}$ for in natura and osmotically pretreated sweet potato slices.

Comparing treatments (Fig. 5), it is possible to observe that for the same moisture content range, the HTST pretreated samples presented drying rates similar to those of the in nature samples. The osmotically pretreated samples (OD and OD + HTST) presented lower drying rates, drying more slowly than the non-osmotically pretreated samples. This behavior can be explained by the difficulty in internal migration of water to the surface due to solids incorporation (OD samples) and hardening of the sample surface (OD + HTST samples). 

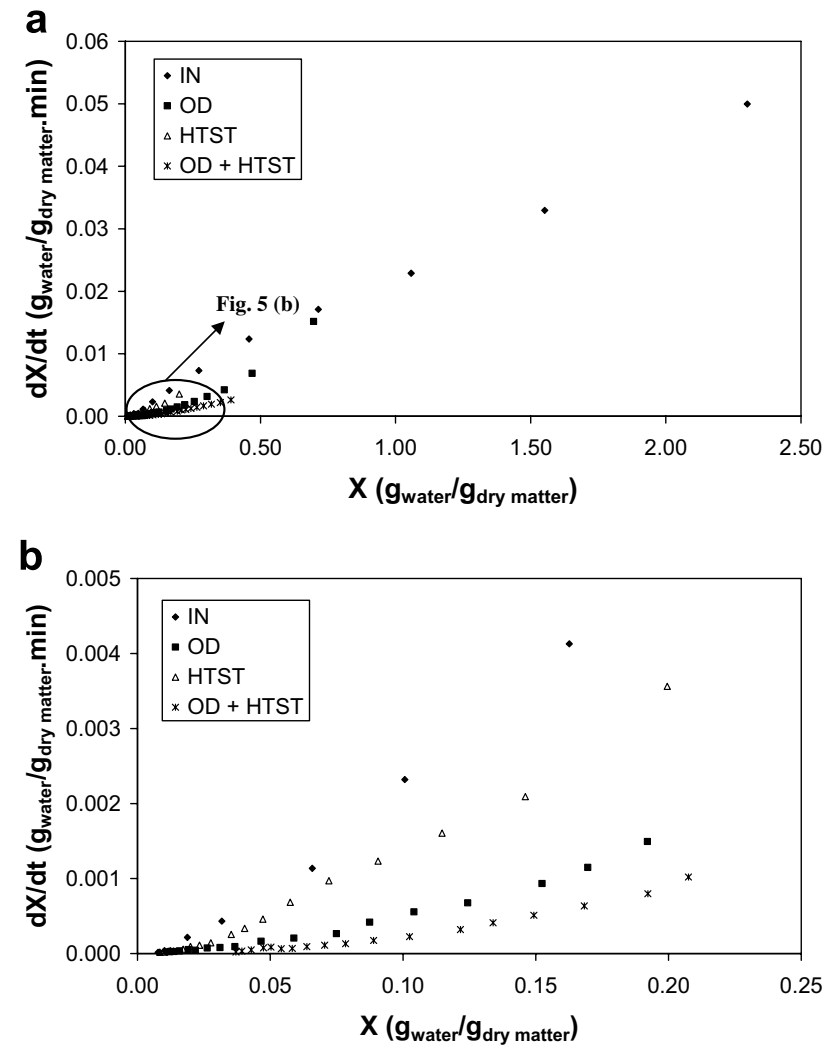

Fig. 5. Drying rates at $T=70^{\circ} \mathrm{C}$ of sweet potato slices.

\section{Conclusions}

The HTST treatment of sweet potato slices showed evidence of the influence of the variables process temperature and time on the values for moisture content, water activity and rehydration, the process time being the most significant variable of the conditions studied. All the empirical models obtained by response surface methodology were considered predictive for the calculation of moisture content, water activity and rehydration.

The best conditions for the HTST treatment of sweet potato slices were a temperature of $160{ }^{\circ} \mathrm{C}$ and time of 22 min for samples with no osmotic pretreatment, and a temperature of $150^{\circ} \mathrm{C}$ and time of $10 \mathrm{~min}$ for samples submitted to osmotic dehydration. Scanning electronic microscopy confirmed pore formation in the internal part and surface sealing of the samples in which puffing (volume increase) occurred during the HTST process. The lowest convective drying times corresponded to the samples only treated by the HTST process. The final product presented an excellent texture and flavor, although the attribute appearance required improvement.

\section{Acknowledgments}

The authors gratefully acknowledge the financial support of CNPq, FAPESP and UNICAMP.

\section{References}

Afzal, T. M., Abe, T., \& Hikida, Y. (1999). Energy and quality aspects during combined FIR-convected drying of barley. Journal of Food Engineering, 42, 177-182.

AOAC (Association of Official Analytical Chemists) (2000). Official methods of analysis (17th ed.). Gaithersburg, Maryland: AOAC.

Bouwkamp, J. C. (1985). Sweet potato products: A natural resource for the tropics. Boca Raton, FL: CRC Press.

Box, G. E. P., \& Behnken, D. W. (1960). Some new three level designs for the study of quantitative variables. Technometrics, 2(4), 455-475.

Jayaraman, K. S., Gopinathan, V. K., Pitchamuthu, P., \& Vijayaraghavan, P. K. (1982). The preparation of quick-cooking dehydration vegetables by high temperature short time pneumatic drying. Journal of Food Technology, 37, 669-678.

Karathanos, V. T., Villalobos, G., \& Saravakos, G. D. (1990). Comparison of two methods of estimation of effective diffusivity from drying data. Journal of Food Science, 55(1), 218-223.

Kim, M. H., \& Toledo, R. T. (1987). Effect of osmotic dehydration and high temperature fluidized bed drying on properties of dehydrated rabbiteye blueberries. Journal of Food Science, 52(4), 980-989.

Marousis, S. N., Karathanos, V. T., \& Saravakos, G. D. (1991). Effect of physical structure of starch materials on water diffusivity. Journal of Food Processing and Preservation, 15, 183-195.

Payne, F. A., Taraba, J. L., \& Saputra, D. (1989). A review of puffing processes for expansion of biological products. Journal of Food Engineering, 10, 183-197.

Sullivan, J. F., Craig, J. C., Jr., Dekazos, E. D., Leiby, S. M., \& Konstange, R. P. (1982). Dehydration blueberries by the continuous explosion-puffing process. Journal of Food Science, 47, 445-448.

Torreggiani, D., Toledo, R. T., \& Bertolo, G. (1995). Optimization of vapor induced puffing in apple dehydration. Journal of Food Science, 60(1), 181-186.

Varnalis, A. I., Brennan, J. G., \& MacDougall, D. B. (2001a). A proposed mechanism of high-temperature puffing of potato. Part I. The influence of blanching and drying conditions on the volume of puffed cubes. Journal of Food Engineering, 48, 361-367.

Varnalis, A. I., Brennan, J. G., \& MacDougall, D. B. (2001b). A proposed mechanism of high temperature puffing of potato. Part II. Influence of blanching and initial drying on the permeability of the partially dried layer to water vapour. Journal of Food Engineering, 48, 369-378.

Varnalis, A. I., Brennan, J. G., MacDougall, D. B., \& Gilmour, S. G. (2004). Optimisation of high temperature puffing of potato cubes using response surface methodology. Journal of Food Engineering, 61, $153-163$. 